\title{
REBROTAMENTO DE CAPIM CANINHA (Andropogon lateralis Nees) SOB O EFEITO DO FOGO ${ }^{1}$
}

\author{
BUDDING OF “CANINHA” GRASS (Andropogon lateralis Nees) UNDER BURNING EFFECT
}

\author{
José Pedro Pereira Trindade ${ }^{2}$ Marta Gomes da Rocha ${ }^{3}$
}

\section{RESUMO}

O presente trabalho foi conduzido com o objetivo de determinar o efeito de disponibilidade de matéria seca de uma pastagem natural, no momento da queima, na posterior taxa de crescimento foliar de Andropogon lateralis Nees. Foi realizado de 1995 a 1996, em área pertencente ao Departamento de Zootecnia da Universidade Federal de Santa Maria. O delineamento experimental utilizado foi o blocos completamente casualisados, com 40 plantas por tratamento. A queima foi realizada em agosto de 1995. Em maio de 1996, na área experimental, foram simulados níveis de disponibilidade de matéria seca através de roçadas com segadeira. Os tratamentos de pastagem foram testemunha sem queima $(2.860 \mathrm{~kg}$ de matéria seca $(\mathrm{MS}) / \mathrm{ha}$ ) e tratamentos de queima com disponibilidades de $2.580,5.000,5.690$ e $6.480 \mathrm{~kg} \mathrm{MS} / \mathrm{ha}$. A avaliação do crescimento foliar foi feita em 600 afilhos marcados de A. lateralis e a metodologia utilizada para determinar o crescimento foliar foi o índice Haun. Houve efeito de queima na forma do aumento da taxa de alongamento de lâminas foliares (TA) de A. lateralis quando a disponibilidade de matéria seca foi de $6.480 \mathrm{~kg} \mathrm{MS} / \mathrm{ha}$. Os demais tratamentos proporcionaram TA semelhantes aos de área não queimada. A. lateralis demonstrou ser uma espécie adaptada ao manejo com fogo, com rápido crescimento após a queima. A escala decimal de Haun demonstrou ser metodologia útil no estudo do rebrotamento de plantas.

Palavras-chave: afilho marcado, taxa de aparecimento de folhas, taxa de alongamento, filocron.

\section{SUMMARY}

The present task was carried out with the objective of determining the effect of available dry matter of a natural grassland during burning in the post Andropogon lateralis Nees leaf growth rate. The work was executed during the years of 1995 and 1996 in an area belonging to the Department of Animal Science of the Universidade Federal de Santa Maria. The experimental design was randomized blocks with 40 plants per treatments. Burning was applied in August of 1995. In May of 1996 levels of dry matter were simulated in the experimental area. The grasslands treatments were controlled without burning (2.860kg of dry matter (DM)/ha) and burned was with dry matter of 2.580, 5.000, 5.690 and $6.480 \mathrm{~kg} \mathrm{DM} / \mathrm{ha}$. The evaluation of the leaf growth was done in 600 tillers of A. lateralis, with 40 marked plants by treatment and the metodology used to determine the leaf growth was the Haun index. There was burn effect on the increase form of $\boldsymbol{A}$. lateralis elongation rate $(E R)$ when the available dry matter was $6.480 \mathrm{~kg}$ MS/ha. The others treatments provided ER similar to the non-burned areas. A. lateralis demonstrated to be a adapted specie to the handling with fire, with fast growth after burning. The decimal scale of Haun demonstrated to be an useful methodology in the study of the budding of plants.

Key words: labelled tiller, budding, appearance rate, elongation rate, phyllochron.

\section{INTRODUÇÃO}

Entre as gramíneas que compõem as pastagens naturais da Depressão Central do Rio Grande do Sul, destaca-se o Andropogon lateralis Nees pela sua ampla distribuição, ocorrendo tanto

\footnotetext{
${ }^{1}$ Parte da Dissertação do primeiro autor, apresentado como um dos requisitos para a obtenção do grau de Mestre em Zootecnia, ao Curso de Pós-graduação em Zootecnia, Departamento de Zootecnia (DZ), Universidade Federal de Santa Maria (UFSM).

${ }^{2}$ Engenheiro Agrônomo, Mestre, aluno do Programa de Pós-graduação em Zootecnia, Universidade Federal do Rio Grande do Sul, bolsista do CNPq.

${ }^{3}$ Engenheiro Agrônomo, Doutor, Professor, DZ, UFSM. Camobi, 97105-900, Santa Maria, RS, Brasil. E-mail:mrocha@ccr.ufsm.br. Autor para correspondência.
} 
em campos úmidos (BOLDRINI \& MARASCHIN, 1991) como em campos mais secos, sendo freqüente e dominante em várzeas e na periferia de banhados (ARAÚJO, 1971). O Andropogon lateralis é uma espécie perene de ciclo estival e porte cespitoso (ARAÚJO, 1971; 1978) com produção máxima de forragem na primavera e no verão e florescimento na primavera, no verão e no outono (BENITEZ \& FERNANDEZ, 1970; ARAÚJO, 1971).

$\mathrm{O}$ fogo tem sido utilizado por produtores, ao longo dos anos, como uma ferramenta para a remoção do material morto de baixa qualidade nutritiva acumulado nas pastagens naturais para que haja promoção de uma dieta de melhor qualidade para os animais (COALDRAKE $\boldsymbol{e t}$ al., 1976; DAMÉ et al., 1997).

Os vegetais possuem forma e hábito de crescimento que são a expressão de seu genótipo. Através do estudo da morfogênese vegetal, pode-se determinar a dinâmica de geração e sua expansão. Assim a morfogênese de plantas pode ser descrita pela taxa de aparecimento de novos órgãos (organogênese), taxa de alongamento (crescimento) e sua taxa de senescência e decomposição, determinando o fluxo de tecidos e o fluxo interno de carbono e nitrogênio. Estas características respondem a variáveis ambientais como temperatura, suprimento de nitrogênio e disponibilidade de água no solo (NABINGER, 1996; LEMAIRE \& CHAPMAN, 1996). Da combinação destas variáveis, surgem as três principais características estruturais das pastagens, que são o tamanho de folha, a densidade de afilhos e o número de folhas verdes por afilho, segundo LEMAIRE \& CHAPMAN (1996).

Por ser o A. lateralis uma espécie bastante freqüente na Depressão Central do Rio Grande do Sul, Brasil, e a queima uma prática importante no manejo das pastagens naturais, o presente trabalho tem como objetivo determinar, em área permanentemente excluída ao pastejo, o efeito da disponibilidade de matéria seca no momento da queima para posterior determinação da taxa de crescimento foliar de A. lateralis.

\section{MATERIAL E MÉTODOS}

O trabalho foi conduzido em área de pastagem natural pertencente ao Departamento de Zootecnia da Universidade Federal de Santa Maria (UFSM). O solo da área experimental, na encosta, é um Podzólico Bruno Acinzentado e na baixada, um Planossolo. As avaliações do crescimento de $\boldsymbol{A}$. lateralis foram feitas na primavera de 1996.

Os tratamentos avaliados basearam-se na disponibilidade de matéria seca no momento da queima em agosto de 1996. Os tratamentos consistiam em: testemunha não queimada com disponibilidade média de $2.860 \mathrm{~kg}$ de matéria seca (MS)/ha e queimados com disponibilidades de $2.580,5.000,5.690$ e $6.480 \mathrm{~kg} \mathrm{MS} / \mathrm{ha}$.

O experimento foi instalado dentro de uma área aproximada de 40ha usada, no mínimo, há 23 anos como pastagem natural. Foi vedado o acesso dos bovinos dentro desta área através de cerca, limitando aproximadamente dois hectares.

Em cada posição topográfica (baixada e encosta), foram delimitados 10 quadrados, com dimensões de $4 \times 4 \mathrm{~m}$ cada, onde foram marcados transecções diagonais. Nas transecções, foram marcadas, de forma aleatória, 10 plantas de $\boldsymbol{A}$. lateralis por transecção. As avaliações foram feitas em três afilhos por planta, devido à diversidade de afilhos em estádios diferentes na planta. Assim foram avaliados um total de 600 afilhos de $\boldsymbol{A}$. lateralis em 40 plantas em cada tratamento.

A estimativa diária da expansão foliar do A. lateralis foi feita de 7/10 a 22/11/1996 através do índice de crescimento de Haun (HIGGINS et al., 1964; HAUN, 1973). Essa metodologia consiste em observações diárias do número de folhas totalmente expandidas e o fracionamento do desenvolvimento previsto da folha em uma série de 10 estádios aproximadamente iguais. Cada estádio representa assim 0,1 do desenvolvimento total previsto. Para uma melhor caracterização dos estádios, foram adotadas características físicas foliares, como comprimento e largura de folha. Foram observadas, também, características complementares como inclinação e abertura da lâmina foliar. A primeira folha identificada de A. lateralis foi marcada com o uso de corretor ortográfico à base de água.

O índice de crescimento Haun em cada período experimental foi calculado da diferença entre índice Haun do dia $(n+1)$ e índice Haun no dia (n). Este valor, multiplicado por 100 e dividido pelo número de dias do período experimental, constitui a taxa diária de alongamento de lâminas foliares no período.

A taxa de aparecimento de folhas, correspondente ao número de folhas por afilho por dia, foi obtida do índice Haun dividido pelo número de dias do período experimental.

O filocrono para o aparecimento de lâminas foliares consecutivas de A. lateralis, nos tratamentos, foi determinado através de análise de regressão entre a soma térmica e o alongamento acumulado em cada período de avaliação, invertendo-se o coeficiente de regressão, conforme descrito por VIÉGAS (1998). Foram utilizados valores médios de alongamento de lâminas foliares. 
Para cada modelo de regressão foi estimado o coeficiente de determinação da taxa de alongamento de lâminas foliares em função da soma térmica.

A soma térmica foi calculada pelo somatório do valor resultante da diferença entre as temperaturas médias diárias e a temperatura base de $10^{\circ} \mathrm{C}$. Esta temperatura base foi utilizada de acordo com COOPER \& TAINTON (1968). A data inicial para o cálculo da soma térmica foi nove de setembro de 1996, data da queima.

A análise estatística do efeito dos tratamentos no rebrotamento do A. lateralis foi feita através de teste de aleatorização (PILLAR, 1999), comparando os valores de taxas de alongamento de lâminas foliares dentro de cada experimento para todos os períodos amostrados. Neste teste, a amostra com os dados observados é recombinada, no presente caso 10.000 vezes, e os quadrados médios produzidos por esta nova população geram uma distribuição de frequiências com a qual a amostra original é comparada. A significância do teste é dada pela comparação entre os dados originais e os dados gerados pela aleatorização. $\mathrm{O}$ programa computacional utilizado foi o MULTIV (PILLAR, 1999). O delineamento experimental utilizado foi blocos ao acaso, nos quais as plantas foram as unidades amostrais, com 40 plantas por tratamento, e o fator de bloqueamento foi a posição topográfica.

\section{RESULTADOS E DISCUSSÃO}

Os resultados mostraram que houve efeito positivo da queima na taxa de alongamento de lâminas foliares de $\boldsymbol{A}$. lateralis somente quando a disponibilidade de matéria seca foi de $6.480 \mathrm{~kg}$ MS/ha. As demais disponibilidades de matéria seca proporcionaram taxas de alongamento semelhantes ao tratamento não queimado (Tabela 1).
A taxa média de alongamento de lâminas foliares foi maior na posição topográfica de baixada do que na encosta, 6,81 e 5,91, respectivamente. CRUZ (1998), no entanto, não observou efeito de posição topográfica na taxa de alongamento de lâminas foliares de A. lateralis.

Até $5.690 \mathrm{~kg}$ de matéria seca (MS) disponível/ha, as taxas de alongamento foram semelhantes, independente da queima (Tabela 1). Observou-se, no entanto, que os tratamentos com disponibilidades inferiores a $5.690 \mathrm{~kg}$ de $\mathrm{MS} / \mathrm{ha}$ mostraram uma tendência de manutenção de taxas de alongamento de lâminas foliares semelhantes, enquanto que este, mostrou uma tendência a uma maior taxa de alongamento (Figura 1).

\begin{tabular}{llll}
\multicolumn{2}{c}{ CORREA \& } \\
CASTILHOS \& ARONOVICH & $(1979)$,
\end{tabular}
EVANGELISTA $\boldsymbol{e} \boldsymbol{t} \boldsymbol{a l}$. (1989), HERINGER \& JACQUES (1998) observaram efeito negativo da queima na produção posterior de forragem, mas estes autores não relataram a disponibilidade de matéria seca no momento da queima. DAMÉ $\boldsymbol{e t}$ al. (1997) e KERSTING (1994) avaliando uma pastagem natural, com resíduo de $2.000 \mathrm{~kg}$ MS/ha no momento da queima, não observaram efeito na taxa de acumulação de matéria seca diária e na produção de matéria seca desta pastagem.

A causa provável da maior taxa de alongamento de lâminas foliares de A. lateralis, observada no tratamento com queimada anual e disponibilidade de $6.480 \mathrm{~kg} \mathrm{MS} / \mathrm{ha}$, está relacionada à disponibilização de nutrientes pela queima (LOUREÇO et al., 1976; CORRÊA \& ARONOVICH, 1979; DOORMAR \& SCHABER, 1992; FERNANDES, 1997). EVANGELISTA $\boldsymbol{e t}$ al. (1989) e CURI et al. (1992), no entanto, afirmam que a quantidade de nutrientes, incorporada pela queima, é baixa, o que provavelmente seja verdadeiro no presente trabalho para os tratamentos com disponibilidade inferior a 6.480kg MS/ha.

As temperaturas médias aparecimento de folhas (número de folhas/afilho/dia) e filocrono (Soma Térmica ST) de A. lateralis, em pastagem natural com diferentes disponibilidades de matéria seca (MS kg/ha), submetida a manejos de queima $(\mathrm{Q}=$ queimado; $\mathrm{NQ}=$ não queimado). Dados médios. Santa Maria - RS, 1996.

\begin{tabular}{cccccc}
\hline MS kg/ha & Queima & Taxa de alongamento & Taxa de aparecimento & Filocrono & $\mathrm{r}^{2}$ (ST e TA) $\dagger$ \\
\hline 2.860 & NQ & $5,8 \mathrm{~B}^{*}$ & $0,058 \mathrm{~B} *$ & 205 & 0,7698 \\
2.580 & $\mathrm{Q}$ & $5,7 \mathrm{~B}$ & $0,057 \mathrm{~B}$ & 214 & 0,8143 \\
5.000 & $\mathrm{Q}$ & $5,7 \mathrm{~B}$ & $0,057 \mathrm{~B}$ & 214 & 0,8060 \\
5.690 & $\mathrm{Q}$ & $6,4 \mathrm{~B}$ & $0,064 \mathrm{~B}$ & 195 & 0,7484 \\
6.480 & $\mathrm{Q}$ & $8,2 \mathrm{~A}$ & $0,082 \mathrm{~A}$ & 151 & 0,7924 \\
\hline
\end{tabular}

*Médias não seguidas de mesma letra diferem estatisticamente nas colunas, segundo teste de aleatorização (PILLAR, 1999) em nível de $1 \%$ de probabilidade de erro

$\dagger$ Coeficiente de determinação da taxa de alongamento de lâminas foliares (TA) em função da soma térmica (ST). observadas ao nível do solo, no momento da queima, foram de $93^{\circ} \mathrm{C}, 149^{\circ} \mathrm{C}, 142^{\circ} \mathrm{C}$ e $184^{\circ} \mathrm{C}$ para os tratamentos de queimadas com resíduos médios de $2.580,5.000,5.690$ e $6.480 \mathrm{~kg}$ MS/ha, respectivamente. Nenhum dos valores observados foi superior aos considerados necessários para alterar as características físicas e químicas do solo observados por 


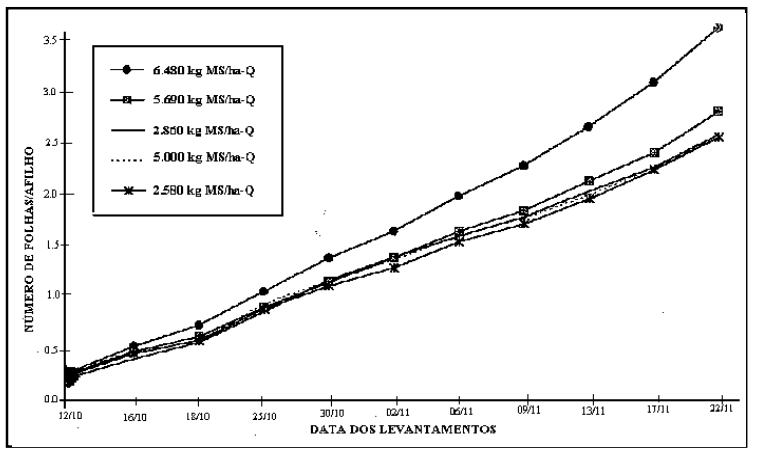

Figura 1 - Alongamento de lâminas foliares acumulado (número de folhas/afilho) de A. lateralis, em pastagem natural com diferentes disponibilidades de matéria seca (MS kg/ha), submetida a manejos de queima $(\mathrm{Q}=$ queimado; $\mathrm{NQ}=$ não queimado). Dados médios. Santa Maria - RS, 1996.

NISHITA \& HAUG (1972) e SERTSU \& SÁNCHEZ (1978), mas os valores observados são muito superiores aos de $20^{\circ} \mathrm{C}$ a $22^{\circ} \mathrm{C}$ observados por DAMÉ et al. (1996).

Mesmo em queimas de alta intensidade, a exposição da superfície do solo a altas temperaturas é rápida (FERNANDES, 1997), não sendo suficiente para afetar as características físicas e químicas do solo (NISHITA \& HAUG, 1972; SERTSU \& SÁNCHEZ, 1978).

A maior temperatura observada deve-se provavelmente ao grande percentual de material senescente na pastagem no momento da queima, com percentual médio de material senescente observado no presente trabalho sendo de 64, 71, 82 e $84 \%$, para os tratamentos de queimadas com resíduos de $2.580,5.000,5.690$ e $6.480 \mathrm{~kg} \mathrm{MS} / \mathrm{ha}$, respectivamente.

$\mathrm{Na}$ tabela 1, observa-se que o menor filocrono foi de 151 graus-dia, no tratamento queimado com disponibilidade de $6.480 \mathrm{~kg} \mathrm{MS} / \mathrm{ha}$, enquanto que, nos demais tratamentos, o filocrono variou entre 195 e 214 graus-dia. O baixo valor de filocrono, observado para A. lateralis, possivelmente esteja associado à maior velocidade de rebrote proporcionada pela disponibilização de nutrientes nos tratamentos queimados, principalmente no tratamento com disponibilidade de $6.480 \mathrm{~kg} \mathrm{MS} / \mathrm{ha}$. Esses valores são inferiores aos 392 graus-dia, observados por CRUZ (1998), para A. lateralis, avaliado sob duas pressões de pastejo. VIÉGAS (1998) trabalhando com Lolium multiflorum, observou valores de filocrono, no estabelecimento e no rebrote dessa cultura de 120 e 150 graus/folha, respectivamente. Os elevados coeficientes de determinação das regressões, por tratamento, na tabela 1, mostram que os valores de filocrono são significativos na estimativa do crescimento de $\boldsymbol{A}$. lateralis.

O efeito dos diferentes tratamentos de queimadas na taxa de aparecimento de folhas foi semelhante ao efeito observado com a variável taxa de alongamento de lâminas foliares. A taxa de aparecimento de folhas de $\boldsymbol{A}$. lateralis foi maior no tratamento com disponibilidade de $6.480 \mathrm{~kg} \mathrm{MS} / \mathrm{ha}$, com 0,082 folhas por dia, o que corresponderia a uma folha totalmente expandida em aproximadamente 12 dias. Não houve diferença de taxa de aparecimento de folhas de A. lateralis entre os demais tratamentos, sendo a média de taxa de aparecimento de folhas de 0,059 folhas por dia, o que corresponderia a uma folha totalmente expandida a cada 17 dias.

A taxa média de aparecimento de folhas de plantas de A. lateralis localizadas na posição topográfica de baixada foi maior do que o observado na encosta, 0,068 e 0,059 folhas por dia, respectivamente.

Os valores de taxa de alongamento, o aparecimento de lâminas foliares e filocrono, observados no presente trabalho, confirmam a afirmação de (CRUZ e BOLDRINI, 1998) de que $\boldsymbol{A}$. lateralis é uma espécie de crescimento lento.

\section{CONCLUSÕES}

O rebrotamento de $\boldsymbol{A}$. lateralis não é afetado, quando existe baixa disponibilidade de matéria seca no momento da queima.

Disponibilidades acima de seis toneladas por hectare de matéria seca, no momento da queima, aceleram o posterior crescimento de A. lateralis.

\section{REFERÊNCIAS BIBLIOGRÁFICAS}

ARAÚJO, A.A. Principais gramíneas do Rio Grande do Sul 3 ed. Porto Alegre : Sulina, 1971. 255p.

ARAÚJO, A.A. Melhoramento das pastagens. 5 ed Porto Alegre: Sulina, 1978. 208p.

BENITEZ, C.A., FERNANDEZ, J.G. Espécies forrageiras de la pradera natural. Fenologia y respuesta a la frequência e severidad de corte. Mercedes, Corrientes, Rep. da Argentina : Instituto Nacional de Tecnologia Agropecuária, Estación Experimental Agropecuária, 1970. 15p. (Série técnica n.10)

BOLDRINI, I.I., MARASCHIN, G.E. Dinâmica de vegetação de uma pastagem natural sob diferentes níveis de oferta de forragem e tipos de solos, Depressão Central, RS. In: REUNIÃO DO GRUPO TÉCNICO REGIONAL EM MELHORAMENTO E UTILIZAÇÃO DE RECURSOS FORRAGEIROS DAS ÁREASS TROPICAL E SUBTROPICAL DO CONE SUL, 1991, Bagé, RS. Anais... Bagé : EMBRAPA, 1991. p.55. 
CASTILHOS, Z.M.S., JACQUES, A.V.A. Caracterização morfológica de espécies nativas e uma cultivada numa pastagem natural submetida a tratamentos de introdução de Trevo vesiculoso cv. Yuchi (Trifolium vesiculosum Savi), ceifa e queima. Anuário Técnico IPZFO, Porto Alegre, v.12, 115-140p, 1985.

COALDRAKE, J.E., TOTHILL, J.C., GILLARD, P Natural vegetation and pasture research. In: SHAW, N.H.; BRYAN, W.W. (eds). Tropical pasture research: principles and methods. Brisbane, : CSIRO, Division of Tropical Agronomy; Bucks: Common Wealth Agricultural Bureaux, 1976. p.51-76

COOPER, J.P., TAINTON, N.M. Light and temperature requeriments for the growth of tropical and temperate grasses. Herbage abstracts, v.38, p.167-176, 1968

CORRÊA, A.N.S., ARONOVICH, S. Influência da queima periódica sobre a vegetação e sobre a fertilidade dos terrenos de pastagens. Revista Sociedade Brasileira Zootecnia, Viçosa, v.8, n.2, p.332-347, 1979.

CRUZ, F.P. da. Dinâmica de crescimento, desenvolvimento e desfolha em Andropogon lateralis Nees. Porto Alegre, 1998. 105 p. Dissertação (Mestrado em Zootecnia) Programa de Pós-graduação em Zootecnia, Universidade Federal do Rio Grande do Sul, 1998.

CRUZ, F.P. da, BOLDRINI, I.I. Dinâmica de crescimento, desenvolvimento e desfolhação em Andropogon lateralis Nees. In: REUNIÃO DO GRUPO TÉCNICO EM FORRAGEIRAS DO CONE-SUL - ZONA CAMPOS, 17 , 1998, Lages, SC. Anais... Lages : Epagri/UDESC, 1998. 156p. p.99.

CURI, N., EVANGELISTA, A.R., GUEDES, G.A. de A. $\boldsymbol{e}$ t al. Queima em pastagens nativas dos campos da mantiqueira (MG): alterações em alguns parâmetros químicos dos solos. In: REUNIÃO DA SOCIEDADE BRASILEIRA DE ZOOTECNIA, 1992, Lavras, SP. Anais... Lavras : Sociedade Brasileira de Zootecnia, 1992. p.402.

DAMÉ, P.R.V., QUADROS, F.L.F. de, KERSTING, C.E.B. et al Efeitos de queima seguido de pastejo ou diferimento sobre o resíduo, temperatura do solo e mesofauna de uma pastagem natural. Ciência Rural, Santa Maria, v.26, n.3, p.391-396, 1996.

DAMÉ, P.R.V., QUADROS, F.L.F. de, KERSTING, C.E.B. et al Efeitos de queima seguido de pastejo ou diferimento sobre a produção, qualidade, cobertura do solo e sistema radicular de uma pastagem natural. Ciência Rural, Santa Maria, v.27, n.1, p.133-137, 1997.

DOORMAR, J.F., SCHABER, B.D. Burning of alfalfa stubble for insect control as it affects soil chemical properties. Canadian J Soil Science, v.72, p.169-175, 1992.

EVANGELISTA, A.R., CARVALHO, M.M. de, CRUZ FILHO, A.B. et al. Efeitos de queimadas no manejo em pastagens nativas. In: REUNIÃO DA SOCIEDADE BRASILEIRA DE ZOOTECNIA, 1989, Porto Alegre, RS. Anais... Porto Alegre : Sociedade Brasileira de Zootecnia, 1989. p.86.
FERNANDES, V.B.B. A queima de campos nativos no planalto Catarinense, em especial no município de Lages: subsídios para uma proposta de gerenciamento ecológico. Porto Alegre, 1997. 110p. Dissertação (Mestrado em Ecologia) - Curso de Pós-graduação em Ecologia, Universidade Federal do Rio Grande do Sul, 1997.

HERINGER, I., JACQUES, A.V.A. Manejo alternativo da pastagem natural em relação às queimadas. In: REUNIÃO DO GRUPO TÉCNICO EM FORRAGEIRAS DO CONESUL - ZONA CAMPOS, 17, 1998, Lages, SC. Anais... Lages : Epagri/UDESC, 1998. 156p. p.122.

HAUN, J.R. Determination of wheat growth-environment relationships. Agronomy Journal, v.65, p.813-816, 1973.

HIGGINS, J.J., HAUN, J.R., KOCH, E.J. Leaf development: index of plant response to environment factors. Agronomy Journal, v.56, p.489-492, 1964.

KERSTING, C.E.B. Avaliação dos efeitos da queima, seguida de pastejo ou diferimento em uma pastagem natural Santa Maria, 1994. 107p. Dissertação (Mestrado em Zootecnia) - Curso de Pós-graduação em Zootecnia, Universidade Federal de Santa Maria, 1994.

LEMAIRE, G., CHAPMAN, D. Tissue flows in grazed plants communities. In: HODGSON, J., ILLIUS, A.W. (ed.). The ecology and managment of grazing systems. Wallingford, UK : CAB INTERNATIONAL, 1996. p.3-36.

LOUREÇO, A.J., SARTINI, H.J., SANTAMARIA, M. O uso do fogo orientado em pastagens de capim jaraguá (Hyparrhenia rufa) consorciado com uma mistura de leguminosas. In: REUNIÃO DA SOCIEDADE BRASILEIRA DE ZOOTECNIA, 1976. Salvador, BA. Anais... Salvador : Sociedade Brasileira de Zootecnia, 1976. p.388.

NABINGER, C. Princípios da exploração intensiva de pastagens. In: PRODUÇÃO DE BOVINOS A PASTO - SIMPÓSIO SOBRE MANEJO DA PASTAGEM, 1996. Piracicaba, SP. Anais... Piracicaba : Fealq, 1996. p.15-96.

NISHITA, H., HAUG, R.M. Some physical and chemical characteristics of heated soils. Soil Science, v.113, n.6, p.422430, 1972.

PILLAR, V.de P. MULTIV User's Guide v.1.3. Porto Alegre : Centro de Ecologia da Universidade Federal do Rio Grande do Sul, 1999. 34p.

SERTSU, S.M., SÁNCHEZ, P.A. Effects of heating on some changes in soil properties in relation to on Ethiopian land management practice. Soil Science Soc Am J, v.42, p.940944, 1978.

VIÉGAS, J. Análise do desenvolvimento foliar e ajuste de um modelo de previsão do rendimento potencial de matéria seca de azevém anual (Lolium multiflorum Lam Porto Alegre, 1998. 159p. Tese (Doutorado em Zootecnia, Área de Concentração Plantas Forrageiras) - Programa de Pósgraduação em Zootecnia, Universidade Federal do Rio Grande do Sul, 1998. 